ORIGINAL ARTICLE

\title{
Patterns of research activity related to government policy: a UK web based survey
}

\section{S S Hawkins, C Law}

See end of article for authors' affiliations

....................

Correspondence to: Dr C Law, Centre for Policy Research, Centre for Paediatric Epidemiology and Biostatistics, Institute of Child Health, 30 Guilford St, London WCIN 1EH, UK; c.law@ich.ucl.ac.uk

Accepted

28 February 2005

\begin{abstract}
Aims: To describe the patterns of child and family health and welllbeing research activity in the fiscal year (FY) 2002/2003 in relation to UK government policies.

Methods: Projects investigating the health and wellbeing of children and families were located through a web based survey of major research funders, including UK government departments and nondepartmental public bodies, research councils, and medical charities. A budget was estimated for each project for the FY 2002/2003, and each project coded according to a framework which reflected government priorities and research methodologies.

Results: There was a substantial amount of project information posted on the websites of the funding organisations, but the level of detail varied. For the FY 2002/2003, 31 organisations were identified that commissioned 567 projects investigating the health and wellbeing of children and families. Based on information from organisations' websites, this represented approximately $3 \%$ of their research budgets. Within this funding area, low proportions of research activity related to health inequalities $19 \%$ of total expenditure on child and family health research), health economic analysis (8\%), primary and secondary prevention (12\%), and children and adolescents at high risk of ill health (14\%).

Conclusions: A limited amount of research activity on children and families health funded in the FY 2002/ 2003 is addressing UK government policy priorities. This suggests the need to commission further research to fill gaps in the evidence.
\end{abstract}

$\mathrm{T}$ he National Service Framework for Children, Young People and Maternity Services (Children's NSF) ${ }^{1}$ in England, National Service Framework for Children, Young People and Maternity Services in Wales ${ }^{2}$ consultation document, and A Framework for Maternity Services in Scotland ${ }^{3}$ reflect the UK government's commitment to the health and wellbeing of children, young people, and families. However, despite the aspiration to evidence based policy, ${ }^{4}$ the evidence base to support policy and practice is lacking. A synthesis of the evidence which informed the English Children's NSF has recently been published, ${ }^{4 a}$ and identified many gaps. Researchers in child and family health have long complained that this area is of low priority to funding organisations..$^{5}$ If the evidence base for policymaking is to improve, then commissioning of new research needs to occur.

The research cycle can be a lengthy process, and many years may elapse between commissioning a project and its results being integrated into the evidence base. ${ }^{6}$ As results from research activity currently ongoing are published, gaps in the evidence base may be filled. On the other hand, if research projects being conducted now are not addressing areas of policy priority, then identified gaps will persist and will need to be addressed by new research. Thus, it is essential that priorities for newly commissioned research on child and family health take into account current research activity. However, this activity has not been systematically assessed or collated.

We have carried out a web based survey of organisations which fund child and family health research. We have assessed patterns of funding for current research activity addressing child and family health, in relation to the policy priorities of the UK government.

\section{METHODS}

Scope

We set out to estimate how much was spent on child and family health research relative to the total expenditure on all research, and within that, how patterns of research activity related to a range of policy priorities. Research for child and family health is funded by many organisations. It is carried out across different sectors of the research community and involves many disciplines and methods, from basic science to health promotion and economic analysis. Our survey attempted to reflect this breadth. We used a modified World Health Organisation (WHO) definition of health, which encompasses wellbeing. ${ }^{7}$ We also included research on predisposing factors that impact directly on the physical, mental, and social health and wellbeing of the child and family, such as health related behaviours (for example, smoking) and services (for example, antenatal care). However, we did not include research that addressed predisposing factors that do not directly impact on child and family health, unless a health component of the research was explicitly stated. For example, research on raising educational attainment would not have been included, whereas research on health promoting schools would have been. Our definition of research was based on the Department of Health (DH) (England) definition. ${ }^{8}$

\section{Identifying funding organisations}

The websites of UK governmental and non-governmental organisations were viewed to determine which organisations fund research related to child and family health. Seven government departments, six non-departmental public bodies (NDPBs), and three research councils were identified.

Medical charities were located through the Association of Medical Research Charities (AMRC). ${ }^{9}$ Charities that fund child and family health research were categorised according to research budget, as found on the AMRC website. All charities with an annual research budget of over $£ 1$ million and who conduct child and family health research were included $(\mathrm{n}=15)$. 
Table 1 Framework for coding current research activity (where appropriate, policies are referenced)

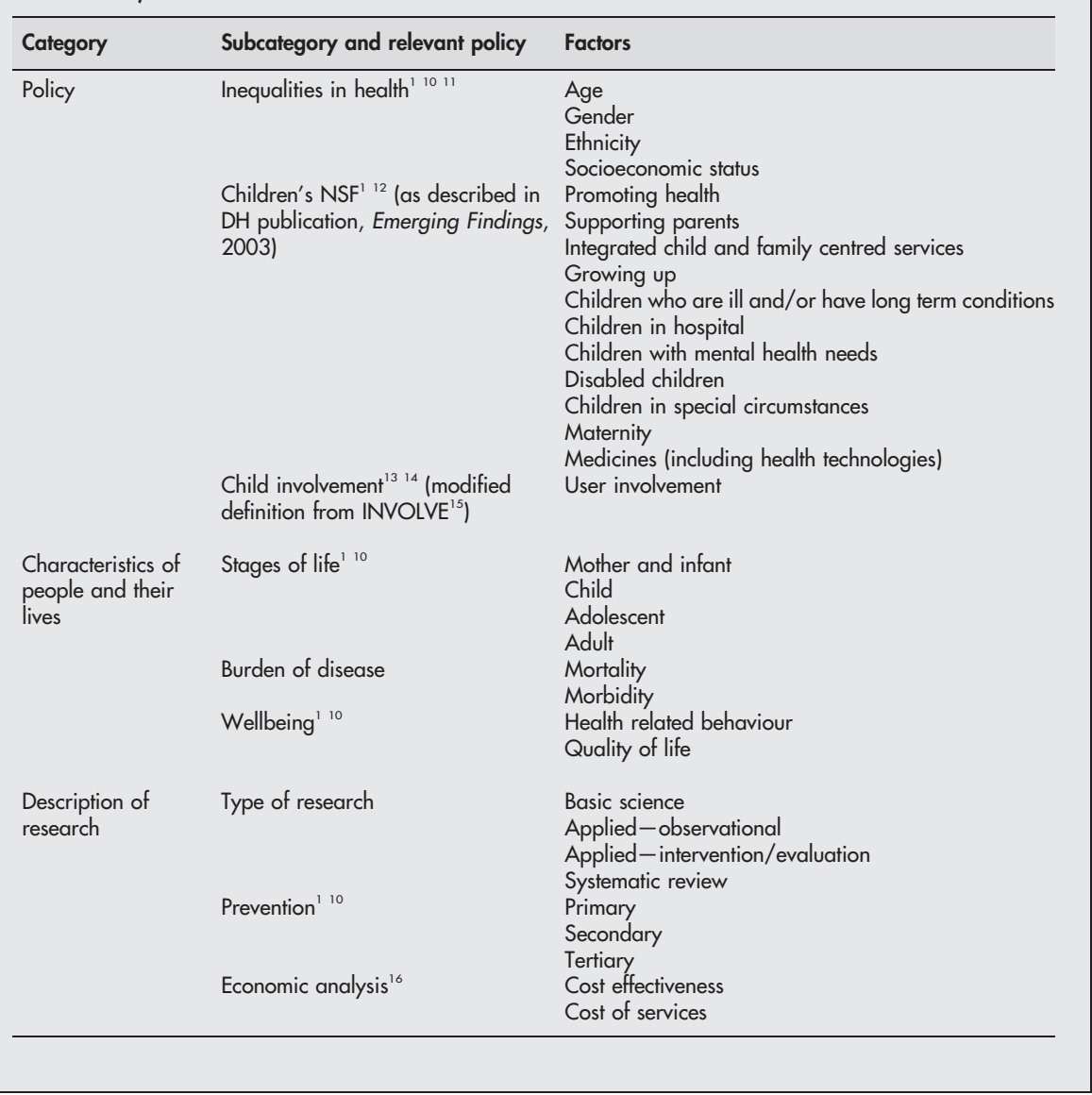

\section{Assessing projects}

We conducted literature and internet searches to determine whether a theoretical framework was available to describe activity, priorities, and gaps in child and family health research activity. We were unable to locate a framework, so we designed our own based on recent UK or English government policies and broad descriptions of research within the medical, public health, and social science fields. The framework is outlined in table 1. Operational definitions for each factor within the framework were constructed at the beginning of the survey.

All projects funded by the selected organisations were identified through hand searching organisations' websites and the DH (England) National Research Register (NRR). ${ }^{17}$ The NRR included information about research projects funded by one government department and 14 medical charities included in the review. However, a study is posted on the NRR only if a researcher submits information about it. We included projects that were receiving funding in the fiscal year (FY) 2002/2003. This was chosen as the most recent period for which information on the internet was most complete at the time of the survey (January-April 2004). Research projects receiving funding in this period were included if they: were conducted at UK institutions or within the UK; involved children below the age of 19; and/or involved fathers, siblings, mothers, pregnancy, or maternity services, as related to child or family health. Basic science research was included if it explicitly stated its relation to child or family health. Projects were excluded if they: did not include any outcomes related to health, health related behaviour, or health promotion; were published in FY 2002/ 2003, but did not state when the project was conducted; and were commissioned from a UK institution, but conducted outside the UK.

We recorded information from the website on the content of each project. Each project was coded under all relevant categories and subcategories of the framework (table 1). The factors are not mutually exclusive, but rather different ways

Table 2 Summary of child and family health (CFH) research activity compared to total research activity by organisation type for the fiscal year $2002 / 2003$

\begin{tabular}{|c|c|c|c|c|}
\hline Organisation type (n) & $\begin{array}{l}\text { CFH research } \\
\text { expenditure* }^{*}\end{array}$ & $\begin{array}{l}\text { Number of CFH } \\
\text { projects* }^{*}\end{array}$ & $\begin{array}{l}\text { Total expenditure } \\
(\% \text { on } \mathrm{CFH})^{*}\end{array}$ & $\begin{array}{l}\text { Total number of projects } \\
(\% \text { on } \mathrm{CFH})^{*}\end{array}$ \\
\hline Government departments (7) & $£ 6190000$ & 147 & $£ 241600000(2.6 \%)$ & $3041(4.8 \%)$ \\
\hline Non-departmental public bodies (6) & $£ 560000$ & 16 & $£ 27480000(2.0 \%)$ & $270(5.9 \%)$ \\
\hline Research councils (3) & $£ 10690000$ & 80 & $£ 482500000(2.2 \%)$ & $2751(2.9 \%)$ \\
\hline Medical charities (15) & $£ 14700000$ & 324 & $£ 312920000(4.7 \%)$ & $4473(7.2 \%)$ \\
\hline Total (31) & $£ 32140000$ & 567 & $£ 1064500000$ (3.0\%) & 10535 (5.4\%) \\
\hline
\end{tabular}

*All values are estimates based on project information from the websites of 31 organisations. 
of classifying research activity. Thus, each project could be coded under multiple factors. We also estimated a budget for the FY 2002/2003 for each project; this was calculated by dividing the total project budget by the duration of the project (in months), then multiplying this value by the number of months the project was receiving funding during the FY 2002/2003. An approximate project budget for each organisation for the FY 2002/2003 was estimated by summing the budgets for the FY 2002/2003 (calculated using the same method) of all projects appearing on its website. We used expenditure on projects and number of projects to describe research activity.

\section{RESULTS}

We found that there was a substantial amount of project information on the websites of the 31 organisations, but that the type of information available varied. Overall, project information from government departments and research councils was more complete than that from NDPBs and medical charities. In the 31 organisations surveyed, we identified 567 projects, with an estimated funding expenditure of $£ 32140000$. All values are estimates of funding and should be regarded as indicative. Table 2 summarises child and family health research activity, expressed as expenditure $(£)$ and number of projects, and compared to total research activity. A low proportion of the total expenditure was allocated to child and family health research.

\section{Analyses of framework}

Analysis of the framework (table 1) was carried out for all organisations together. Analysis based on expenditure showed similar patterns of activity to analysis based on number of projects; therefore, we present only the former. Since projects could cover more than one area and factors within the framework were not mutually exclusive, percentages may add up to more than 100 .

\section{Policy}

Children's NSF

Most projects investigated at least one aspect of the Children's NSF (table 3). Most expenditure was allocated to projects on maternity, medicines, and children who are ill and/or have long term conditions. Smaller proportions were spent on projects investigating support for parents, integrated child and family centred services, children in special circumstances, and children in hospital. Projects that were not coded as being relevant to the Children's NSF tended to be basic science.

\section{Inequalities}

A project was coded as including inequalities if its description stated that the project examined age, gender, ethnicity, and/ or socioeconomic factors. Only 46 projects, approximately $9 \%$ of the total child and family health expenditure, investigated at least one inequalities factor. Socioeconomic issues (6\%) were the most frequently investigated type of inequality.

\section{User involvement}

The description of 13 projects stated that the experience of children, carers or parents, "representatives" or advocates for patients, or community groups was collected as part of the research. Approximately $1 \%$ of the child and family health research expenditure supported projects in this area.

\section{Characteristics of people and their lives Stages of life}

We found that projects were not evenly distributed across the stages of life. More funding was spent on projects involving mothers and infants (49\%) and children (52\%), compared to adolescents $(23 \%)$.
Burden of disease and wellbeing

Approximately $4 \%$ of expenditure was for projects that investigated mortality, $40 \%$ on morbidity, $11 \%$ on health related behaviour, and $6 \%$ on quality of life.

\section{Description of research \\ Type of research}

Most expenditure was allocated to projects on basic science or using observational methods, with less spent on intervention studies and systematic reviews (table 4). Intervention projects were classified as primary, secondary, or tertiary prevention. Of the intervention projects, approximately three times the amount of funding supported secondary prevention $(40 \%)$ projects compared to primary prevention (14\%). Similarly, significantly more funding supported tertiary prevention $(48 \%)$ projects compared to primary prevention (14\%).

\section{Health economic analysis}

We located only 36 projects, $8 \%$ of the total expenditure, which included analyses of cost effectiveness or cost of services.

\section{DISCUSSION}

We surveyed child and family health research activity from the FY 2002/2003 and mapped these onto a framework that reflected UK policy and research methodologies. We used a web based search strategy to gather information on organisations' research activities through project information provided on their websites. Our analyses showed that a relatively low proportion of funding from these organisations supported child and family health research. Analysis based on number of projects exhibited similar patterns of activity (not shown). The organisations that we sampled were chosen to include those who spent the most money on child and family health research, including some charities where the funding of such research is the primary aim. Thus, this proportion seems likely to be an over- rather than underestimate.

Our results also indicate that there was little child and family health research activity targeting UK policy priority areas. Although the NHS Plan for England, ${ }^{18}$ Tackling Health Inequalities: A Programme for Action, ${ }^{11}$ and Choosing Health: Making Healthier Choices Easier ${ }^{19}$ emphasise the importance of reducing inequalities across social groups, we found that few projects investigated health inequalities. Similarly, our survey revealed that organisations spent little on research for children with disabilities, mental health needs, and in special circumstances, despite these areas being prioritised in the Children's NSF ${ }^{1}$ and Every Child Matters. ${ }^{10}$ The evidence base to inform development of the currently inadequate services for adolescents and the transition from childhood to adult life is weak, ${ }^{1}$ but we found that there was relatively little research activity within these areas. Despite the emphasis on prevention in the Children's NSF, ${ }^{1}$ Every Child Matters, ${ }^{10}$ and Choosing Health: Making Healthier Choices Easier, ${ }^{19}$ we found little research activity focusing on primary and secondary prevention or addressing health promotion. The Wanless report, Securing Good Health for the Whole Population, discusses strengthening the evidence base on the cost effectiveness of clinical and public health interventions, and on altering health related behaviours. ${ }^{16}$ Our survey suggests that a limited number of projects are addressing either area.

Our results are based on project information located on organisations' websites. We chose this method in order to achieve complete ascertainment of organisations, as the main alternative, a postal survey, often suffers from response bias. ${ }^{20}$ We found that most organisations' websites contained significant amounts of information about their research 
Table 3 Child and family health (CFH) research activity by themes in the Children's NSF

\begin{tabular}{lll}
\hline Children's NSF & $\begin{array}{l}\text { CFH research } \\
\text { expenditure }\end{array}$ & $\begin{array}{l}\text { \% CFH research } \\
\text { expenditure }\end{array}$ \\
\hline Supporting parents & $£ 180000$ & 0.5 \\
Integrated child and family centred services & $£ 370000$ & 1 \\
Children in special circumstances & $£ 620000$ & 2 \\
Children in hospital & $£ 940000$ & 6 \\
Disabled children & $£ 2070000$ & 7 \\
Growing up & $£ 2280000$ & 7 \\
Promoting health & $£ 2410000$ & 9 \\
Children with mental health needs & $£ 2810000$ & 23 \\
Medicines & $£ 7390000$ & 28 \\
Children who are ill and/or have long term conditions & $£ 8990000$ & 30 \\
Maternity & $£ 9530000$ & 77 \\
Total Children's NSF expenditure & $£ 24620000$ & \\
Total CFH research expenditure & $£ 32140000$ & \\
\hline Since projects could cover more than one area and factors were not mutually exclusive, percentages may add up to \\
more than 100.
\end{tabular}

activities. However, the level of detail and completeness of information varied between organisations-most included project descriptions and budgets, but some only reported a project title, which limited our ability to describe the activity. It is likely that some types of research were easier to identify than others. For example, research on medicines and health technologies may have been easier to ascertain than those addressing integrated services or the effects of education or environmental factors on health. We were also unable to ascertain what information was not placed on websites and therefore our assessment may not represent the total amount of research activity funded by the selected organisations. In order to reduce the amount of missed information, each organisation's project list was hand searched as well as searching the National Research Register. ${ }^{17}$ We recognise that our results are estimates of funding and can only be regarded as indicative. However, as inaccuracies might be expected to apply equally to both child/family and non-child/family research activity, the proportion of child/family to nonchild/family research activity should be correctly estimated. Furthermore, the information we used is the main interface between funding organisations and the public. As many of the organisations which spend the most money on research have a remit to be open with or engage the public, ${ }^{21-23}$ we would expect that the information available would not be biased or misleading.

We did not survey all organisations that fund child and family health research and focused on those with large expenditures. We recognise that sampling in this way risks introducing bias; however, we surveyed organisations with high expenditure, as these have more potential for strategic shifts in direction. In addition, we did not include research commissioned by organisations in the commercial sector, social care charities, or many smaller funders. The commercial sector probably accounts for a high expenditure on child and family health research, not all of which is motivated by improvements to health. For example, the food industry is likely to have different motivations in investigating dietary behaviour in children to health promotion researchers. We were unable to include social care charities in the review because we found that their websites tended to publish findings from their commissioned research rather than details of currently funded research activity. Therefore, we were unable to analyse this information using the same methodology. We were also unable to collate information on research activity which is not explicitly funded as project based research; this may include the time of academic or NHS staff. Since important aspects of our framework were based on DH (England) policy, we only assessed the research portfolio commissioned by the English Health Department. Policy priorities for health in the devolved countries are similar, ${ }^{4}$ but we have not assessed the extent to which funding from these Health Departments addresses them.

The survey method we used was new and we have been unable to identify similar surveys. Our method of analysis was based on work by the National Cancer Research Institute (NCRI) Partner Organisations, ${ }^{24}$ which also used expenditure on projects to assess patterns of funding in cancer research organisations, though did not use a web based approach. Similar to our survey, the NCRI found that research on prevention received relatively little funding and this funding has informed current commissioning to address this gap. ${ }^{25}$ The NCRI analysis found a high proportion of expenditure was on basic science. While the proportion spent on basic science in our survey was also quite high $(38 \%)$, we suspect that this is an underestimate, as we were often unable to determine from the information provided on the websites whether basic science projects were relevant to child and family health.

We found the use of websites to carry out a survey had considerable advantages, but was also challenging in terms of completeness and level of detail of information. As the

Table 4 Child and family health (CFH) research activity by type of research

\begin{tabular}{llc}
\hline Type of research & $\begin{array}{l}\text { CFH research } \\
\text { expenditure }\end{array}$ & \% CFH research expenditure \\
\hline Systematic review & $£ 690000$ & 2 \\
Intervention & $£ 7220000$ & 22 \\
Basic science & $£ 12340000$ & 38 \\
Observational methods & $£ 15600000$ & 49 \\
Total type of research expenditure & $£ 32130000$ & 100 \\
Total CFH research expenditure & $£ 32140000$ & \\
\hline
\end{tabular}

Since projects could cover more than one area and factors were not mutually exclusive, percentages may add up to more than 100 . 


\section{What is already known on this topic}

- The UK government has prioritised the health and wellbeing of children, young people, and families

- Recent reports have highlighted gaps in knowledge and the need for evidence based policy and practice

internet becomes the main interface between organisations and the public, such information constraints may lessen. Information on organisations' websites would be improved if each project's description included an abstract and lay summary, as well as the amount of funding and duration of the project. The use of the world wide web for this type of research would benefit from further testing and evaluation, as it has the capacity to be a cost effective method and to increase the availability of information to the public.

Our findings suggest that the gaps in the evidence underlying policy priorities are unlikely to be filled by research that is currently ongoing. It also accords with anecdotal accounts from child and family health researchers that this area of research receives a low proportion of funding from the major funders. ${ }^{5}$ Some of the gaps in the evidence are being addressed by commissioning activity. For example, the Department of Health (England) has recently commissioned a research network on medicines for children, ${ }^{26}$ and a consortium of partners are funding the National Prevention Research Initiative, ${ }^{25}$ though this is not focused on children. Funding is also likely to be required to develop capacity, so that a skilled research workforce is in place to conduct high quality research within these policy priority areas. Several areas of policy priority are likely to require further investment in research if policy aims such as reduction in inequalities in health, cost effective, child centred services, and improved health for all children, including those who are disabled, vulnerable, or mentally ill, are to become a reality.

\section{ACKNOWLEDGEMENTS}

We would like to thank Dr Carolyn Davies for her advice and support. We would also like to thank our colleagues at the Institute of Child Health for their feedback.

\section{Authors' affiliations}

S S Hawkins, C Law, Institute of Child Health, University College London, London, UK

Funding: Research at the Institute of Child Health and Great Ormond Street Hospital for Children NHS Trust benefits from R\&D funding received through the NHS Executive

\section{Competing interests: none}

This work was undertaken by $\operatorname{Dr}$ Catherine Law and Ms Summer Hawkins who received funding from the Department of Health. The views expressed in the publication are those of the authors and not necessarily those of the Department of Health.

\section{REFERENCES}

1 Department of Health, Department for Education and Skills. National service framework for children, young people and maternity services. London: The Stationery Office, 2004

2 Welsh Assembly Government. National service framework for children, young people and maternity services in Wales: consultation document. Cardiff: Welsh Assembly Government, 2004.

\section{What this study adds}

- Priorities established by UK government policies are not reflected in current child and family health research activity

- There is limited current research activity focusing on health inequalities, economic analysis, primary and secondary prevention, and children and adolescents at high risk of ill health

3 Scottish Executive Health Department. A framework for maternity services in Scotland. Edinburgh: Scottish Executive Health Department, 2001.

4 Black N. Evidence based policy: proceed with care. BMJ 2001;323:275-9.

4a Department of Health. Evidence to inform the National Service Framework for Children, Young People and Maternity Services, http//www.dh.gov.uk/ assetRoot/04/11/24/04/04112404.pdf (accessed 10 August 2005).

5 Anon. UK paediatric clinical research under threat. Arch Dis Child 1997;76:1-3.

6 Royle J, Steel R, Hanley B, et al. Getting involved in research: a guide for consumers. Winchester: Consumers in NHS Research Support Unit, 2001.

7 World Health Organisation. Preamble to the Constitution of the World Health Organization as adopted by the International Health Conference, New York, 19-22 June, 1946; signed on 22 July 1946 by the representatives of 61 States (Official Records of the World Health Organization, no. 2, p. 100) and entered into force on 7 April, 1948

8 Department of Health. Draft research governance framework for health and social care, http://www.dh.gov.uk/assetRoot/04/02/08/96/ 04020896.doc (accessed 12 December 2003)

9 Association of Medical Research Charities. http://www.amrc.org.uk (accessed 10 January 2004).

10 The Department for Education and Skills. Every child matters. London: The Stationery Office, 2003.

11 Department of Health. Tackling health inequalities: a programme for action. London: Department of Health, 2003.

12 Department of Health. Getting the right start: the national service framework for children, young people, and maternity services-emerging findings. London: Department of Health, 2003.

13 Department of Health. Listening, hearing and responding: Department of Health involving children and young people. London: Department of Health, 2003.

14 Department of Health. Building on the best: choice, responsiveness and equity in the NHS. London: The Stationery Office, 2003.

15 INVOLVE. Definition of consumers, http://www.invo.org.uk/faq4.htm (accessed 15 December 2003).

16 Wanless D. Securing good health for the whole population. London: The Stationery Office, 2004.

17 Department of Health. National research register, http://www.updatesoftware.com/national/ (accessed 2 October 2004).

18 Department of Health. The NHS plan: a plan for investment, a plan for reform. London: The Stationery Office, 2000.

19 Department of Health. Choosing health: making healthier choices easier. London: The Stationery Office, 2004.

20 Hager MA, Wilson S, Pollak TH, et al. Response rates for mail surveys of nonprofit organizations: a review and empirical test. Nonprofit and Voluntary Sector Quarterly 2003;32:252-67.

21 Department for Constitutional Affairs. Code of practice on access to government information, 2nd edn. London: Department for Constitutional Affairs, 1997.

22 Medical Research Council. Mission statement, http://www.mrc.ac.uk/index/ about/about-mission.htm (accessed 22 November 2004).

23 Wellcome Trust. Aims and objectives, http://www.wellcome.ac.uk/strategy/ aims/ (accessed 22 November 2004).

24 National Cancer Research Institute. Strategic analysis 2002: an overview of cancer research in the UK directly funded by the NCRI partner organisations. London: National Cancer Research Institute, 2002.

25 National Cancer Research Institute. National prevention research initiativecall for proposals 2004, http://www.mrc.ac.uk/index/funding/fundingspecific_schemes/funding-calls_for_proposals/funding-npri.htm (accessed 22 November 2004)

26 University of Liverpool. Liverpool to lead $£ 20 \mathrm{~m}$ Department of Health initiative to develop medicines for children. http://www.liv.ac.uk/newsroom/ press_releases/2005/03/medicines_for_childr.htm (accessed 10 August 2005). 